\title{
UTILIZAÇÃO DE MAPA CONCEITUAL COMO FERRAMENTA DE ANÁLISE DE TRABALHOS CIENTÍFICOS
}

\author{
M. S. T. ARAÚJO ${ }^{1}$ e R. FORMENTON ${ }^{2 *}$ \\ ${ }^{1}$ Universidade Cruzeiro do Sul \\ ${ }^{2}$ Instituto Federal de Educação, Ciência e Tecnologia de São Paulo - IFSP \\ ricardofor@uol.com.br
}

Artigo submetido em maio/2014 e aceito em fevereiro/2015

DOI: 10.15628/holos.2015.2130

\section{RESUMO}

Geralmente os mapas conceituais são utilizados como instrumento direcionado para as atividades de ensino e de avaliação, apoiando a sistematização dos conhecimentos construídos. Neste artigo propomos a utilização desse instrumento como ferramenta de análise de trabalhos científicos, caracterizando outra forma de uso deste recurso. Assim, com apoio da teoria cognitivista ausubeliana, exemplificamos esta proposta a partir da construção de mapas conceituais baseados na dissertação de mestrado intitulada "As fontes de energia automotiva abordadas sob o enfoque CTS no ensino profissionalizante", propiciando uma visão rápida e abrangente de todo o percurso metodológico escolhido em sua construção.

PALAVRAS-CHAVE: Teoria cognitivista ausubeliana, Mapas Conceituais, Análise de Trabalho Científico.

\section{USE OF CONCEPT MAP AS A TOOL FOR ANALYSIS OF SCIENTIFIC WORK}

\begin{abstract}
Generally, we use concept maps as a tool directed to teaching and assessment, supporting the systematization of knowledge built. In this article we propose the use of this instrument aiming at the analysis of scientific work, featuring another form to use this tool. Thus, with support the Ausubel cognitive theory,
\end{abstract}

we aim to build a concept map of a scientific work entitled "The automotive energy sources approached under STS focus in professional teaching", providing an embracing and a quick overview of all the methodological approach chosen for its building. 


\section{INTRODUÇÃO}

De uma forma geral, mapas conceituais são basicamente diagramas que mostram relações entre conceitos. Mais especificamente, podem ser interpretados como diagramas hierárquicos que procuram mostrar a organização conceitual de uma disciplina ou de parte dela. Em outras palavras, seu formato deriva da estrutura conceitual de uma disciplina ou de um corpo de conhecimentos e podem ser utilizados como instrumento de ensino e/ou aprendizagem (MOREIRA, 2006).

Neste trabalho buscamos estender a utilização dos mapas conceituais propondo que esta ferramenta seja empregada como um recurso auxiliar para que pesquisadores possam sistematizar as informações obtidas a partir da análise de trabalhos acadêmicos, como artigos científicos, dissertações e teses. O uso desse recurso pode oferecer apoio na etapa de fichamento dos trabalhos, importante momento vivido no desenvolvimento das pesquisas de diversas naturezas, visto que o levantamento bibliográfico tende a dar suporte em seu planejamento e elaboração.

Neste sentido, objetivamos neste artigo propor a utilização de mapas conceituais visando à análise de um trabalho científico, caracterizando outra possibilidade de uso deste instrumento e para alcançar este objetivo consideramos a dissertação intitulada "As fontes de energia abordadas sob o enfoque CTS no ensino profissionalizante" (FORMENTON, 2011). Esta dissertação apresenta um corpo de conhecimentos que se relaciona com metodologias educacionais destinadas ao desenvolvimento de aspectos de cidadania entre alunos de um curso profissionalizante por intermédio de várias ações pedagógicas que consideramos apropriadas.

Vale ressaltar que a referida pesquisa foi realizada no Instituto Federal de Educação, Ciência e Tecnologia (IFSP), campus Guarulhos - Brasil, no curso profissionalizante de nível médio em Automação Industrial que comporta conteúdos voltados especificamente para a área de trabalho dos estudantes.

Desta forma, um mapa conceitual que explicita as etapas da construção e estruturação da dissertação enfocada poderá ilustrar como os mapas conceituais podem auxiliar os pesquisadores a organizar os conteúdos de um trabalho científico analisado, a metodologia de pesquisa empregada, bem como outros aspectos de interesse de forma rápida, abrangente e com vistas a analisar seus elementos estruturais mais relevantes.

Com relação à dissertação utilizada como exemplo, cabe destacar que o currículo do ensino médio profissionalizante em Automação Industrial do Instituto Federal de Educação, Ciência e Tecnologia de São Paulo (IFSP), campus Guarulhos, onde foi realizada a pesquisa, é formado por um conjunto de disciplinas direcionadas à formação na área de atuação em que o aluno pretende trabalhar. Portanto, esse currículo tem a pretensão de preparar esse aluno para sua atividade específica fornecendo formação técnica adequada para iniciar uma carreira em alguma indústria do seu interesse.

O Plano de Desenvolvimento Institucional (PDI) do IFSP aponta para a necessidade não só de uma formação específica de qualidade, mas que também contemple o desenvolvimento da cidadania como eixo da proposta pedagógica para os alunos dos cursos profissionalizantes, 
chamando atenção para suas posições, decisões e atitudes de maneira a considerar as expectativas de uma sociedade cada vez mais complexa e exigente.

A questão que norteou o desenvolvimento desse trabalho pode ser assim expressa: Como os Mapas Conceituais podem ser empregados como ferramenta de sistematização e análise de trabalhos científicos nas etapas de fichamento e levantamento bibliográfico de pesquisas?

Como parte da metodologia utilizada neste trabalho, buscamos simultaneamente à exemplificação do uso dos Mapas Conceituais na modalidade aqui descrita, apresentar e discorrer sobre conceitos e informações relacionados à dissertação abordada, visando facilitar o entendimento de como esta modalidade de uso dos Mapas Conceituais está sendo proposta, contribuindo para a organização e representação de um determinado campo de conhecimento (NOVAK e CAÑAS, 2007).

\section{REFLEXÕES SOBRE O MAPA CONCEITUAL}

Para Novak e Cañas (2007) os mapas conceituais são gráficos hierarquicamente apresentados para organizar e representar um campo de conhecimento. Considerando a forma e os objetivos que estamos propondo para a utilização deste recurso como ferramenta de análise de trabalhos científicos em etapas de fichamento e levantamento bibliográfico, podemos enumerar algumas características específicas que são fundamentais, tais como:

a) O material deve ser conceitualmente claro;

b) As palavras utilizadas na construção de cada mapa conceitual devem ser familiares;

c) Os mapas conceituais pretendem organizar o trabalho científico de forma abrangente e rápida;

d) A construção das estruturas conceituais deve facilitar o entendimento detalhado do campo de conhecimento abordado no trabalho científico analisado.

A utilização dos Mapas Conceituais como ferramenta de apoio ao pesquisador em sua etapa de levantamento bibliográfico, possui algumas vantagens para a organização das informações relacionadas ao campo de conhecimento do trabalho analisado, indo ao encontro do que asseveram Moreira e Massini (2006) quando abordam a utilização de mapas conceituais, ou seja:

a) Enfatiza a estrutura conceitual do trabalho científico analisado;

b) Enfatiza a importância dos conceitos envolvidos, que são então apresentados em ordem hierárquica;

c) Facilita a sistematização e fichamento dos detalhes da estruturação do trabalho, como a Metodologia da Pesquisa e a Fundamentação Teórica;

d) Promove uma visão integrada do tema abordado;

e) Permite elaborar uma "listagem" daquilo que foi abordado no trabalho;

f) Facilita o entendimento do tema abordado no referido trabalho científico.

Conforme Moreira (2011), podemos dividir a aprendizagem em três formas distintas: cognitiva, afetiva e psicomotora. Apesar da existência de certa adesão entre elas, o autor ressalta 
suas diferenças, enfatizando que na Teoria de Aprendizagem proposta por David Ausubel é considerada, prioritariamente, a aprendizagem cognitiva dos indivíduos:

\begin{abstract}
A aprendizagem cognitiva é aquela que resulta no armazenamento organizado de informações na mente do ser que aprende, e esse complexo organizado é conhecido como estrutura cognitiva. A aprendizagem afetiva resulta de sinais internos ao indivíduo e pode ser identificado com experiências tais como prazer e dor, satisfação ou descontentamento, alegria ou ansiedade. Algumas experiências afetivas sempre acompanham as experiências cognitivas. Portanto, a aprendizagem afetiva é concomitante com a cognitiva. A aprendizagem psicomotora envolve respostas musculares adquiridas por meio de treino e prática, mas alguma aprendizagem cognitiva é geralmente importante na aquisição de habilidades psicomotoras. A teoria de Ausubel focaliza primordialmente a aprendizagem cognitiva (MOREIRA, 2011, p. 159).
\end{abstract}

Assim, seguindo a proposta deste trabalho, a figura 1 mostrada adiante ilustra um Mapa Conceitual que foi elaborado com vistas a organizar o conteúdo de uma dissertação de mestrado acadêmico em ensino de ciências, defendida na Universidade Cruzeiro do Sul em 2011. Desta forma, o Mapa Conceitual apresentado pode auxiliar a compreensão dos percursos escolhidos para a construção da referida pesquisa promovendo, concomitantemente, a observação do rol de considerações envolvidas na construção do trabalho científico.

Esta modalidade de uso do mapa conceitual se apoia no fato deste recurso possibilitar a elaboração de um diagrama capaz de organizar a estrutura conceitual de um corpo de conhecimentos, podendo ser utilizado tanto como um instrumento de ensino e/ou aprendizagem (MOREIRA, 2006), quanto na organização de informações tipicamente encontradas nos levantamentos bibliográficos.

Cabe destacar que o Plano de Desenvolvimento Institucional (PDI) do IFSP aponta para uma formação ampliada no ensino profissionalizante e, por esse motivo, a pesquisa abordou as contribuições do movimento Ciência, Tecnologia e Sociedade (CTS) para uma pretendida formação cidadã que considere os impactos da Ciência e da Tecnologia (C\&T) para a sociedade e para o ambiente. Por intermédio de diversas metodologias de ensino como pesquisas, seminários, reflexões e debate foram propiciadas uma gama de reflexões CTS, articulando o ensino de Física presente na disciplina de Máquinas Elétricas, com o tema "Fontes de Energia Automotiva" e com os pressupostos do movimento CTS.

\title{
3 UTILIZANDO O RECURSO MAPAS CONCEITUAIS NA ANÁLISE DE UMA DISSERTAÇÃO
}

Um mapa conceitual é uma ferramenta que pode ser utilizada para diversas finalidades, entre elas, como instrumento didático, de avaliação e para análise de conteúdo. Assim, este recurso pode ser empregado: 1ㅇ) como instrumento didático, não dispensando explicações do professor; $2^{\circ}$ ) como instrumento de avaliação, permitindo testar os conhecimentos dos alunos a fim de classificá-los de alguma maneira, diferentemente da usual; 3) como instrumento de análise de conteúdo, podendo comportar uma aula de uma disciplina de um curso (MOREIRA, 2006). 
Propomos aqui uma quarta alternativa de utilização dos mapas: a de ser recurso auxiliar na sistematização de informações sobre trabalhos acadêmicos, complementando o fichamento dos trabalhos em etapas de levantamento bibliográfico por parte de pesquisadores. Em outras palavras, propomos a utilização de mapas conceituais visando à análise de um trabalho científico, caracterizando outra possibilidade de uso deste instrumento.

Para construção dos mapas conceituais utilizamos o software CmapTools, disponibilizado gratuitamente pelo Institute for Human \& Machine Cognition (IHMC) da Universidade da Florida (EUA). Vale ressaltar que o referido software facilita a elaboração e o desenho dos mapas, agilizando consideravelmente a etapa de notação dos conceitos.

Como podemos observar no mapa conceitual da Figura 1, a apresentação sintetiza as ideias utilizadas para a construção da dissertação de mestrado utilizada como exemplo representando, de forma particular, os conceitos mais relevantes. Cabe lembrar que cada indivíduo desenhará um mapa conceitual diferente, com conceitos e ligações diferentes, sobre um mesmo campo de conhecimento, sendo o exemplo mostrado apenas uma das inúmeras possibilidades.

Notamos neste primeiro mapa conceitual, do seu lado esquerdo, a metodologia da pesquisa-ação utilizada na dissertação como forma de atuação do professor-pesquisador para desenvolvimento da formação educacional dos alunos. Assim, a pesquisa-ação como metodologia de pesquisa foi direcionada para a alfabetização científica dos alunos, encontrando respaldo teórico em vários autores, definindo adequadamente o significado de se adotar uma proposta de intervenção baseada nesta metodologia na direção de transformar uma situação problema, ou ainda, sugerir uma solução para um problema coletivo local ou mundial.

Observando o lado direito do mapa conceitual da figura 1, notamos que a fundamentação teórica da pesquisa analisada é baseada em Vygotsky (2000) e Morin (2008), que forneceram os conceitos que serviram de sustentação para as ações pedagógicas. Vale ressaltar aqui que a ligação central da visão vygotskyana no processo de desenvolvimento das pessoas é a formação de conceitos.

Moreira e Massini (2006) reforçam este pensamento uma vez que consideram que o conjunto próprio de conceitos assimilados pelo homem é que lhe permite situar-se no mundo direcionando adequadamente suas ações. Vale frisar que o recurso dos Mapas Conceituais não fez parte das ações metodológicas empregada na referida dissertação, mas aqui utilizamos como ferramenta que mostra um diagrama indicando relações entre conceitos (MOREIRA, 2006), tornado-se de grande valia na medida em que permite esclarecer a organização conceitual de um determinado campo de conhecimento (MOREIRA e MASSINI, 2006).

Ao centro do mapa conceitual, podemos observar que o movimento Ciência, Tecnologia e Sociedade (CTS) é o enfoque norteador do processo de intervenção do autor da dissertação, embasando discussões e reflexões que procuraram superar um ensino conteudista. Vários autores nacionais e internacionais discutem o movimento CTS como sendo uma forma de chamar atenção da sociedade para os impactos sócio-ambientais da C\&T constituindo, portanto, uma possibilidade para uma formação científica ampliada para os alunos, conforme anunciam Moraes e Araújo (2012), Cachapuz (2005), Santos (2005), Auler (2003) e Dagnino e Thomas (2003). 
O movimento CTS é, assim, um caminho de fundamental importância para a formação científica adequada dos alunos do ensino profissionalizante, pois de muitas formas eles estão diretamente ligados a estudos que envolvem aspectos de Ciência e Tecnologia no curso profissionalizante.

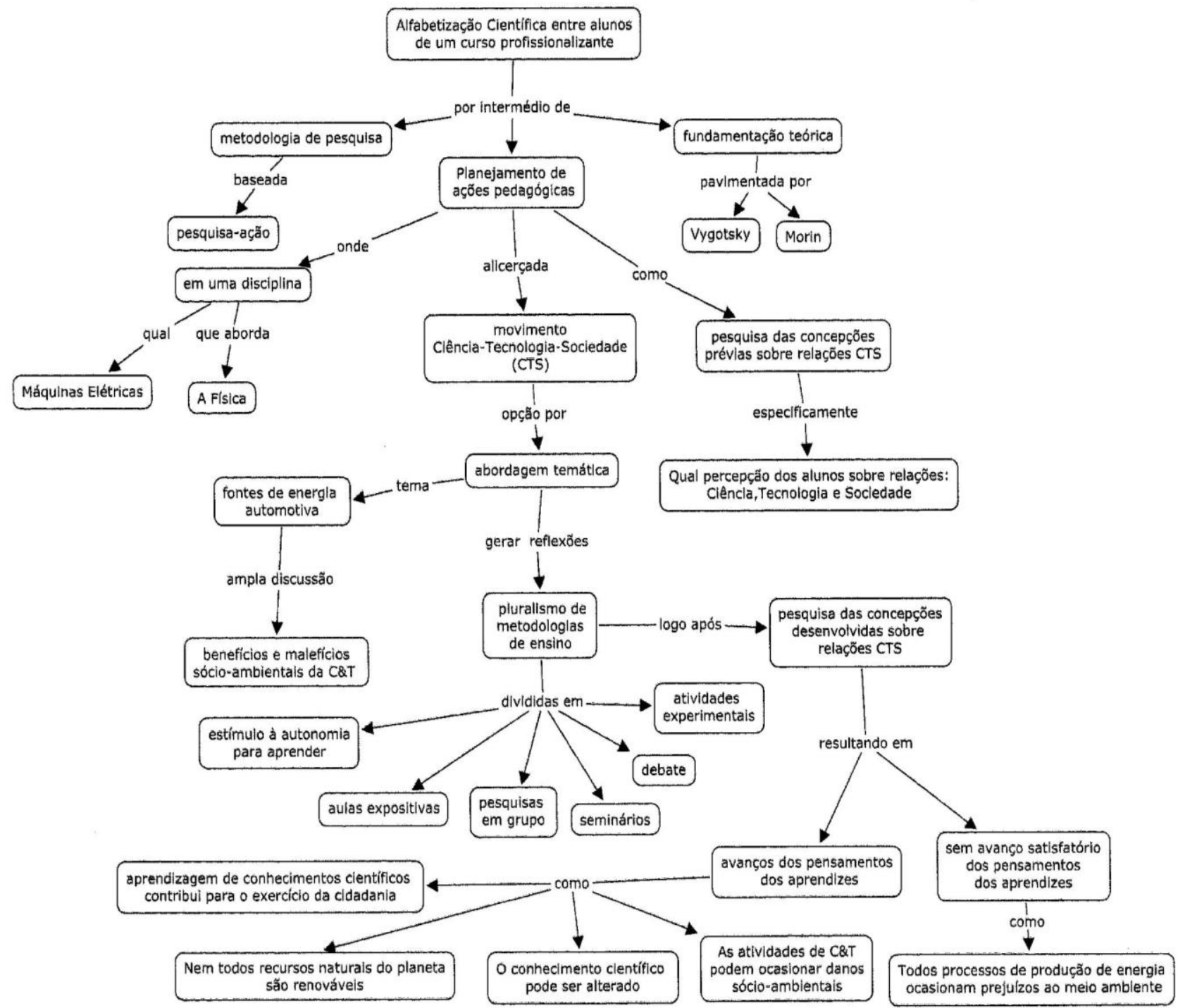

Figura 1 - Mapa Conceitual da dissertação de Mestrado abordada e que visa à formação cidadã de alunos de um curso profissionalizante.

Segundo aponta Moreira (2006, p. 14), Ausubel defende que novas ideias sobre um determinado assunto recebem adesão dos pensamentos dos indivíduos se elas puderem ser ancoradas em conceitos adequadamente compreendidos anteriormente. Assim, o conceito mais importante, relativo à teoria ausubeliana, é o de aprendizagem significativa (MOREIRA, 2006), considerando que novos aportes conceituais são adquiridos pelas pessoas, amparados em conceitos já existentes em sua estrutura cognitiva. Desta forma, o conceito que já é desenvolvido, existindo de fato na estrutura cognitiva de um indivíduo, Ausubel chama de conceito subsunçor, que vai alicerçar novas aprendizagens. 


\section{MAPAS CONCEITUAIS COMPLEMENTARES PARA ANÁLISE DA DISSERTAÇÃO}

Entendemos que outros mapas conceituais podem ser apresentados como forma de complementar o anterior (Figura 1), fornecendo detalhamento dos elementos que estruturam a construção da referida dissertação de mestrado.

Inicialmente, julgamos oportuno um primeiro exemplo de como podemos utilizar o Mapa Conceitual para fornecer detalhes da fundamentação teórica da dissertação analisada, que se baseia nos conceitos defendidos por Edgar Morin (Figura 2).

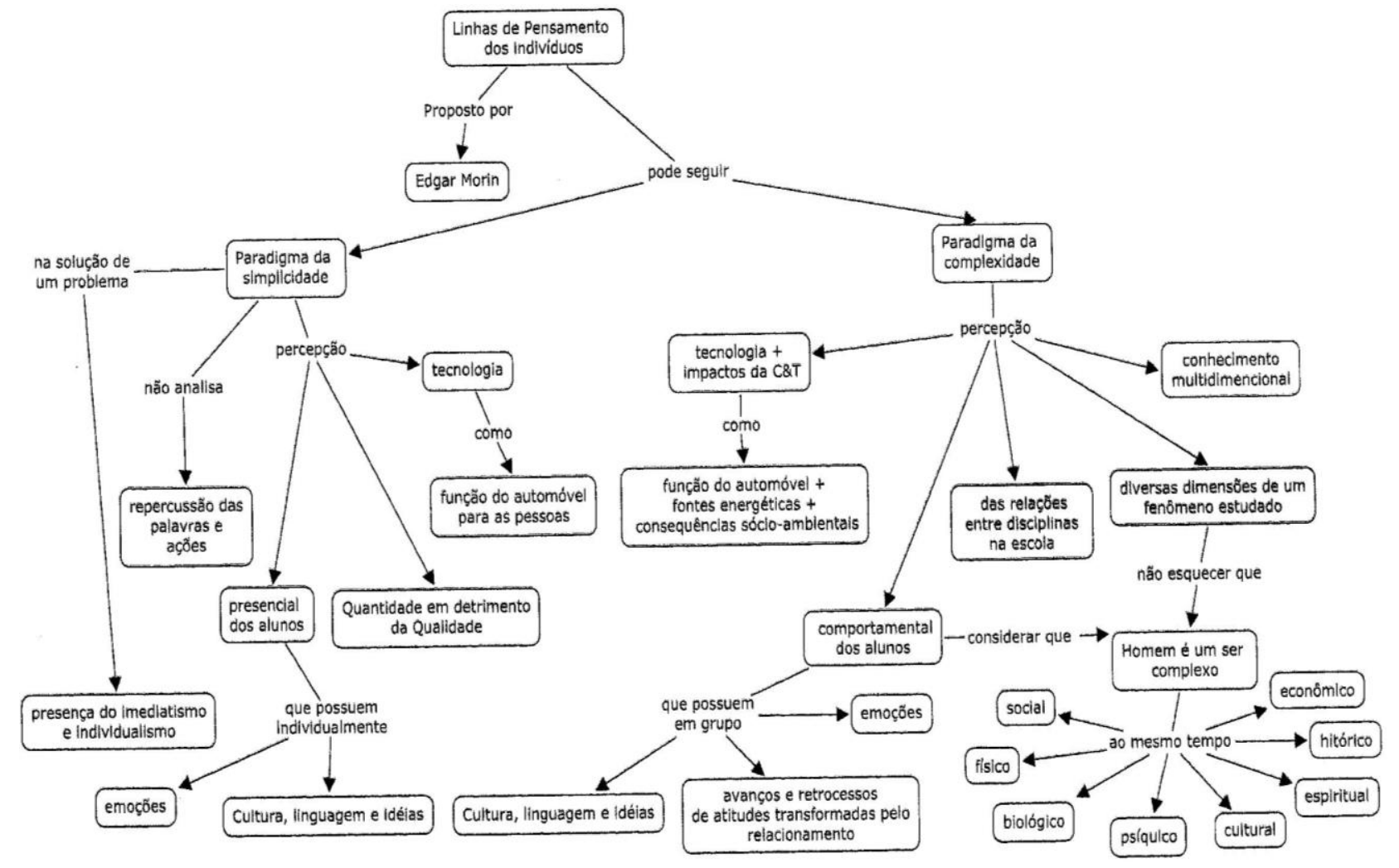

Figura 2 - Mapa Conceitual da fundamentação teórica da dissertação baseada nas teorias de Edgar Morin.

Observamos que o detalhamento dos aspectos da fundamentação teórica utilizada na dissertação amplia o entendimento da sua estrutura, oportunizando uma organização didática mais detalhada de como as ideias e conceitos de Edgar Morin podem possibilitar o desenvolvimento do pensamento das pessoas envolvidas na pesquisa ali descrita (Figura 2).

Entendemos assim que cada elemento da estrutura da dissertação, ou de um específico trabalho científico que esteja sendo analisado, pode servir de base para a elaboração de um mapa conceitual formando, desta forma, uma rede de conhecimentos sobre o assunto específico retratado.

Outra complementação da figura 1 é apresentada na figura 3 a seguir, mostrando organizadamente por meio de um novo Mapa Conceitual a Metodologia de Pesquisa utilizada na construção da referida pesquisa de mestrado. 


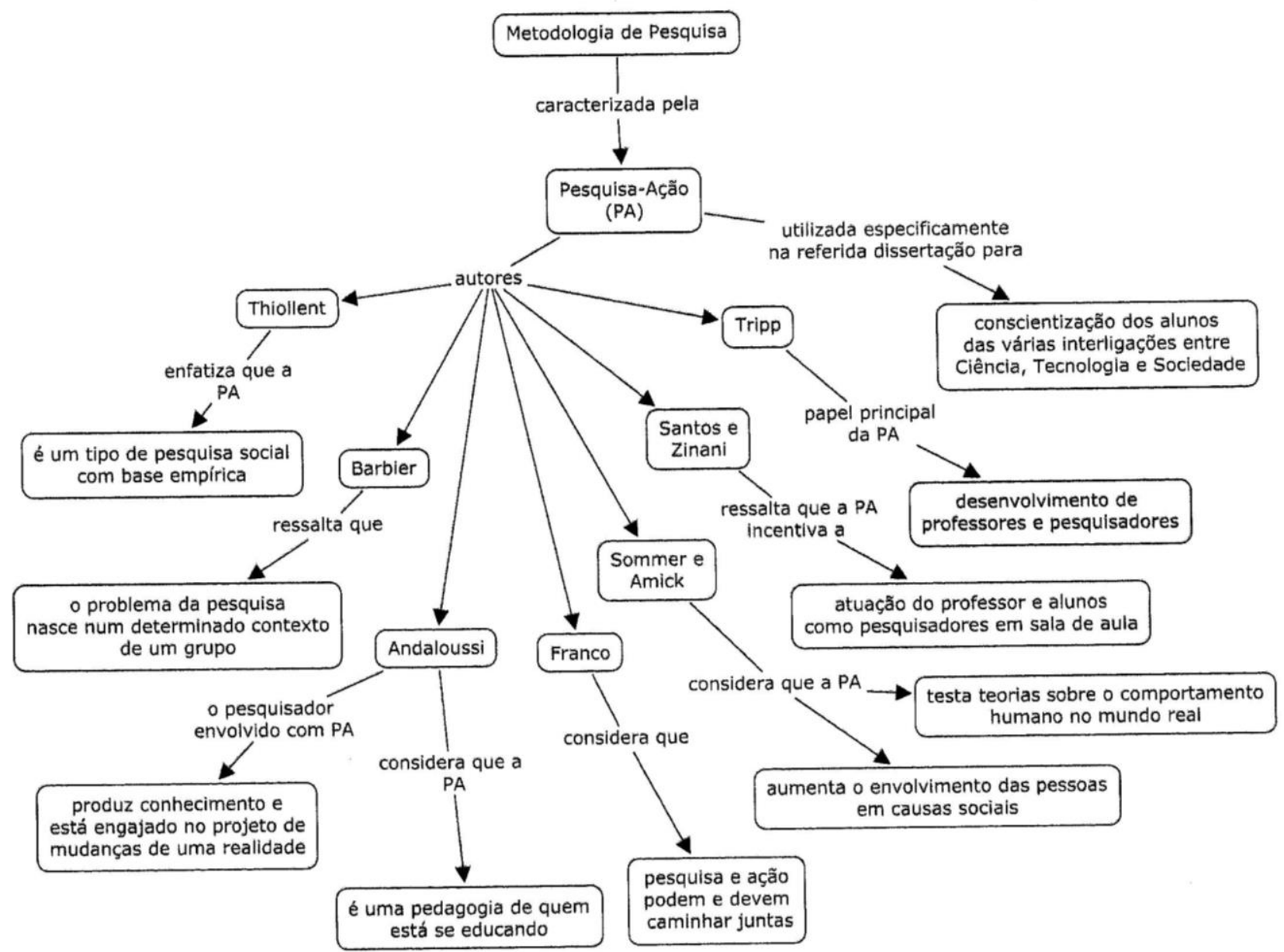

Figura 3- Mapa Conceitual da Metodologia de Pesquisa da dissertação baseada na Pesquisa-Ação.

A Metodologia de Pesquisa-Ação, utilizada na construção da pesquisa "As fontes de energia automotiva abordadas sob o enfoque CTS no ensino profissionalizante", está alicerçada em vários autores, como podemos observar no mapa conceitual da figura 3. De forma geral, a Pesquisa-Ação, como o próprio nome revela, necessita de ações conjuntas: 1á) pesquisa de uma situação real, a partir de dados coletados em campo; 2a) participação efetiva dos encaminhamentos para solução dos problemas revelados. Uma característica importante desta metodologia é a de ser cíclica, ou seja, não se esgota em etapas estanques de pesquisa da situação e a organização de uma ação posterior final, única ou definitiva.

A pesquisa-ação contempla movimentos cíclicos das etapas de pesquisa e de ação objetivando, no caso da referida dissertação, proporcionar mudanças de atitudes, valores e entendimentos dos aprendizes sobre assuntos de ciência e tecnologia envolvendo a vida em sociedade, empregando atividades investigativas e estimulando uma maior participação dos alunos.

Uma última aplicação do Mapa Conceitual como ferramenta de análise de um trabalho científico é apresentado a seguir na figura 4, que ilustra o conjunto de intervenções pedagógicas (Metodologias de Ensino) utilizadas no desenvolvimento da dissertação que serviu de exemplo para este trabalho, onde foi proposto o desenvolvimento de aspectos de cidadania envolvendo alunos de um curso profissionalizante de nível médio em assuntos que envolvem Ciência e Tecnologia: 


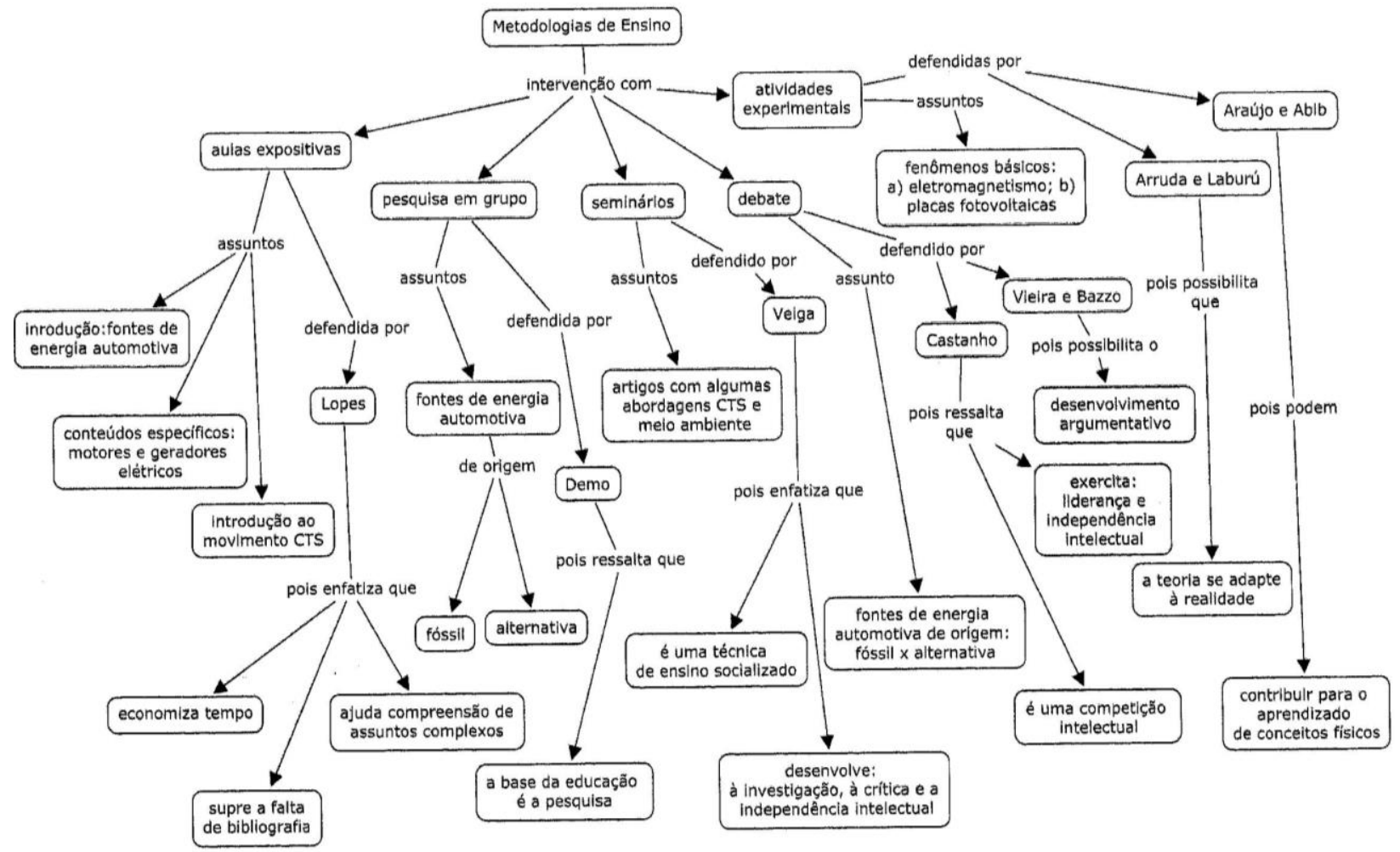

Figura 4 - Mapa Conceitual das metodologias de ensino utilizadas nas intervenções pedagógicas da dissertação de mestrado.

A Constituição Federal (CF), em seu artigo 205, indica a necessidade de preparar os indivíduos para o exercício da cidadania e sua qualificação para o trabalho, visando o pleno desenvolvimento da pessoa. Na mesma direção, a Lei de Diretrizes e Bases da Educação Nacional (LDB) - Lei 9.394, artigo 2 - ratifica o artigo 205 da CF, enfatizando a necessidade de preparar o alunado para o exercício da cidadania e sua qualificação profissional.

De maneira convergente a estes aspectos legais, na dissertação analisada foi utilizado o pluralismo de ideias e concepções pedagógicas, que é um dos princípios da LDB e, como podemos observar no Mapa Conceitual da figura 4, várias metodologias de ensino foram escolhidas para facilitar o desenvolvimento de aspectos de cidadania dos alunos. Cada uma das metodologias de ensino é amparada por autores específicos, como mostra o referido Mapa Conceitual. Neste sentido, Laburú e Carvalho (2005, p. 79) ressaltam a importância da utilização de múltiplas ações pedagógicas objetivando o desenvolvimento do pensamento entre os alunos, asseverando que:

Na sua tradução em estratagemas de ensino, a prática pluralista não revela, portanto, ser contra a Instituição de um conjunto único, frio, restrito, de regras que se pretenda serem universalmente aceitas e principalmente válidas e verdadeiras para toda e qualquer situação de aluno, professor, sala de aula, faixa etária, escola, etnia cultural, lingüística, matéria, conceito, etc. A compreensão de que o processo de aprendizagem pode e precisa ser elaborado em obediência a regras fixa e universais é, ao mesmo tempo, fantasiosa e perniciosa. É fantasiosa, pois implica uma visão demasiado simplista das capacidades dos aprendizes e das circunstâncias que lhes estimulam ou provocam o desenvolvimento. É perniciosa, porque a tentativa de emprestar vigência às 
regras nos conduz a acentuar algumas qualificações, em detrimento de uma formação humanitária mais geral. (LABURÚ e CARVALHO, 2005, p. 79).

Como é próprio da natureza dos Mapas Conceituais, os conceitos e relações apresentados no interior dos mapas elaborados para este artigo, não tem a pretensão de esgotar a gama de argumentos e reflexões conectados aos autores referenciados. Em outras palavras, cada mapa conceitual apresenta um rol de conceitos que estão conectados com a dissertação de mestrado usada como exemplo de uso desta ferramenta de análise, correspondendo a importantes aspectos do tema abordado, sendo explicitados e organizados de uma maneira específica neste trabalho.

\section{CONSIDERAÇÕES FINAIS}

Para Severino (2007), o fichamento da documentação bibliográfica deve ser realizado paulatinamente, à medida que o pesquisador realize as leituras dos livros, capítulos de livros, artigos, dissertações, teses e outros textos acadêmicos, conforme a temática de interesse. Esse autor aponta ainda que "não há tamanho padronizado para essas fichas de documentação, ficando a critério de cada um o seu formato. Tanto mais que agora elas podem ser digitadas em micro, formando documentos/arquivos, diretórios e pastas" (SEVERINO, 2007, p. 70).

No caso da dissertação utilizada como exemplo neste trabalho, entendemos que a visualização das fases de sua construção, envolvendo ações direcionadas para formação cidadã de alunos de um curso profissionalizante de nível médio, fica mais bem explicitada e de entendimento facilitado devido à apresentação sintetizada por intermédio de mapas conceituais.

Vale ressaltar que é preciso tomar os devidos cuidados para que os Mapas Conceituais não sejam demasiadamente complexos ou confusos, dificultando com isso a sua posterior compreensão e utilização.

Os encaminhamentos para resolver o problema apontado na dissertação abordada, seu encaminhamento metodológico e sua fundamentação teórica podem ser amplamente compreendidos pelo pesquisador por intermédio do recurso dos Mapas Conceituais, contribuindo para os seus próprios objetivos de investigação.

Embora Novak e Cañas (2007) sugiram que geralmente são suficientes entre 15 a 25 conceitos para construção de um "esqueleto" sobre um assunto, por não ser uma regra rígida consideramos apropriado neste artigo construir os mapas ultrapassando ligeiramente as indicações dos referidos autores em três dos quatro mapas, ou seja, no primeiro mapa (figura 1) empregamos 31 conceitos, no segundo mapa (figura 2) constam 29, no terceiro mapa (figura 3) aparecem 19 e no quarto mapa (figura 4) são apresentados 33 conceitos. Acreditamos que, desta forma, apresentamos uma organização mais adequada para os objetivos que se destina esse artigo inserindo detalhes que consideramos relevantes para elucidar a construção das etapas do trabalho científico utilizado como exemplo.

Reconhecemos, por fim, que um mapa conceitual nunca está terminado, podendo receber aperfeiçoamentos decorrentes de novas revisões e colaborações, agregando novos conceitos e reposicionando outros a fim de ampliar o campo de conhecimento estudado, cabendo ao pesquisador avaliar os objetivos de sua pesquisa e efetuar as modificações e complementações que julgar necessárias. 


\section{REFERÊNCIAS BIBLIOGRÁFICAS}

1. AULER, D. Alfabetização científico-tecnológico: um novo "paradigma"? Ensaio, v. 5, n. 1, p. 69-83. Disponível em: <http://www.portal.fae.ufmg.br/seer/index.php/ensaio/issue/view/ 8/showToc>. Acesso em: 10 mar. 2014.

2. BRASIL. Constituição da República Federativa do Brasil, 1998.

3. . Lei 9.394/1996 - Lei de Diretrizes de Bases da Educação Nacional (LDB), 2008.

4. . Lei no 11.892 - Rede Federal de Educação Profissional. Ministério da Educação. Brasília, 2008.

5. CACHAPUZ, A. et al. A necessária renovação do ensino das ciências. São Paulo: Cortez 2005, $263 p$.

6. DAGNINO, R.; THOMAS, H. (org.). Ciência, Tecnologia e Sociedade: uma reflexão latinoamericana. São Paulo: Cabral Editora e Livraria Universitária, 2003, 190 p.

7. FORMENTON, R. 2011. Dissertação de mestrado. As fontes de energia abordadas sob o enfoque CTS no ensino profissionalizante. Disponível em: <http://ms.ensinodeciencias. cruzeirodosul.edu.br/index.php/menudissertacoes.html>. Acesso em 10 de abr. 2014.

8. INSTITUTE FOR HUMAN \& MACHINE COGNITION (IHMC), Universidade da Florida (EUA) (Org.). Software CmapTools. Disponível em: < http://cmap.ihmc.us/conceptmap.html>. Acesso em 1 de mar. 2014.

9. LABURÚ,C.E.; CARVALHO,M. Educação Científica: controvérsias construtivistas e pluralismo metodológico. Londrina: EDUEL, 2005, 119 p.

10. MORAES, J.U. P.; ARAÚJO, M.S.T. O Ensino de Física e o Enfoque CTSA: Caminhos para uma educação cidadã. São Paulo: Editora Livraria da Física, 2012, 144 p.

11. MOREIRA, M.A. Teorias de Aprendizagem. São Paulo: EPU, 2011, 242 p.

12. MOREIRA, M.A. A teoria da aprendizagem significativa e sua implementação em sala de aula. Brasília: Editora Universidade de Brasília, 2006, 186 p.

13. MOREIRA, M.A.; MASINI, E.F.S. Aprendizagem Significativa: A teoria de David Ausubel. São Paulo: Centauro, 2006, $112 \mathrm{p}$.

14. MORIN,E. Ciência com Consciencia. 11 ed., Rio de Janeiro: Bertrand Brasil, 2008, 350 p.

15. NOVAK, J.D.; CAÑAS, A.J. 2007. La teoría subyacente a los mapas conceptuales y cómo construirlo. Disponível em: <http://cmap.ihmc.us/publications/ResearchPapers/TeoriaCmaps /TeoriaSubyacenteMapasConceptuales.html>. Acesso em: 1 de mar. 2014.

16. SANTOS, M.E.V.M. Que educação? tomo I. Lisboa: Santos-Edu, 2005, 138p.

17. SEVERINO, A.J. Metodologia do Trabalho Científico. 23 ed., São Paulo: Cortez, 2007, 304 p.

18. VYGOTSKY, L.S. A construção do pensamento e da linguagem. São Paulo: Martins Fontes, 2000, 496p. 